\title{
Effect of vegetation on soil water retention and storage in a semi-arid alpine forest catchment
}

\author{
Chao WANG ${ }^{1}$, ChuanYan ZHAO ${ }^{2 *}$, ZhongLin $X^{3}$, Yang WANG ${ }^{2}$, HuanHua PENG ${ }^{1}$ \\ ${ }^{1}$ College of Resources and Environmental Sciences, Lanzhou University, Lanzhou 730000, China; \\ ${ }^{2}$ School of Life Sciences, Lanzhou University, Lanzhou 730000, China; \\ ${ }^{3}$ College of Resources and Environmental Sciences, Xinjiang University, Urumqi 830046, China
}

\begin{abstract}
The runoff generated from mountainous regions is recognized as the main water source for inland river basins in arid environments. Thus, the mechanisms by which catchments retain water in soils are to be understood. The water storage capacity of soil depends on its depth and capacity to retain water under gravitational drainage and evapotranspiration. The latter can be studied through soil water retention curve (SWRC), which is closely related to soil properties such as texture, bulk density, porosity, soil organic carbon content, and so on. The present study represented SWRCs using HYDRUS-1D. In the present study, we measured physical and hydraulic properties of soil samples collected from Sabina przewalskii forest (south-facing slope with highest solar radiation), shrubs (west-facing slope with medium radiation), and Picea crassifolia forest (north-facing slope with lowest radiation), and analyzed the differences in soil water storage capacity of these soil samples. Soil water content of those three vegetation covers were also measured to validate the soil water storage capacity and to analyze the relationship between soil organic matter content and soil water content. Statistical analysis showed that different vegetation covers could lead to different soil bulk densities and differences in soil water retention on the three slope aspects. Sand content, porosity, and organic carbon content of the $P$. crassifolia forest were relatively greater compared with those of the $S$. przewalskii forest and shrubs. However, silt content and soil bulk density were relatively smaller than those in the $S$. przewalskii forest and shrubs. In addition, there was a significant linear positive relationship between averaged soil water content and soil organic matter content $(P<0.0001)$. However, this relationship is not significant in the $P$. crassifolia forest. As depicted in the SWRCs, the water storage capacity of the soil was $39.14 \%$ and $37.38 \%$ higher in the $P$. crassifolia forest than in the $S$. przewalskii forest and shrubs, respectively, at a similar soil depth.
\end{abstract}

Keywords: vegetation; soil water storage; soil properties; soil water retention curve; forest catchment; Heihe River

Citation: Chao WANG, ChuanYan ZHAO, ZhongLin XU, Yang WANG, HuanHua PENG. 2013. Effect of vegetation on soil water retention and storage in a semi-arid alpine forest catchment. Journal of Arid Land, 5(2): 207-219.

The runoff generated from mountainous regions is recognized as the main source for inland river basins in arid environments. Forests play a crucial role in runoff generation, on the one hand, by affecting hydrological processes such as precipitation interception and evapotranspiration (Eagleson, 2002), and on the other hand, by bringing about significant variability in soil properties, consequently modifying the amount of rainwater available for infiltration (Zheng et al., 2008).
Therefore, a clear understanding of the effects of forest management practices on vegetation structure and soil properties is especially important with regard to water yield. However, most available literatures simply dealt with the influence of vegetation structure on hydrological processes (Gash et al., 1980, 1995; Liu, 1997; Bellot and Escarre, 1998; Xiao et al., 1998, 2000; Teske and Thistle 2004; Murakami, 2006; Staelens et al., 2008; Miralles et al., 2010) and few

*Corresponding author: ChuanYan ZHAO (E-mail: nanzhr@lzb.ac.cn) Received 2012-07-23; revised 2012-11-03; accepted 2012-12-14

C Xinjiang Institute of Ecology and Geography, Chinese Academy of Sciences, Science Press and Springer-Verlag Berlin Heidelberg 2013 
with the effect of vegetation on soil properties that control soil water retention and storage (Wang et al., 2008, 2009; Zhang et al., 2011).

Soil water is an important water source for vegetation development. Changes of soil water may greatly affect tree species diversity and forest canopy structure. It is also one of the most important factors controlling hydrological processes (Castillo et al., 2003; Seeger et al., 2004). However, soil water is influenced by vegetation type and soil properties. Different vegetation and soil types have different water infiltration capacities. Getting a better understanding of the interactions between vegetation, soil and water flux is central to environmental management for more water yield in water-limited environments. Soils under natural forests tend to be relatively porous because trees loosen the soil and accumulate more organic matter with high infiltration rates. Thus, forest cover influences the water retention capacity in forest sites, and in turn increases the overall water storage capacity (Lüscher and zürcher, 2003). Sarah (2002) found that shrubs affect soil properties through soil-vegetation interaction that resulted in higher infiltration rate and greater soil water retention capacity than in inter-shrub areas after rain. Zhang et al. (2011) found forested ecosystems had greater soil water retention capacity than shrub ecosystems because of the thick humus. Similar results were found by Wang et al. (2008), who discovered that the topsoil layer under high vegetation cover, as with the highly organic fine-grained soils and litter layer, reduced the thermal conductivity and increased the water infiltration and water hold capacity, altering the active soil-water-heat relationship.

In mountainous regions, topography and microclimate affect water and energy balance, consequently affecting the spatial distribution of vegetation. The variations of vegetation can affect soil properties such as bulk density, porosity, and organic matter content, thereby altering the water storage capacity of soil.

Heihe River Basin is the second largest inland river basin in China. In the past two decades, the basin has attracted considerable attention from the government and the scientific community because of the conflicting water demands between ecological restoration and agriculture use in its upper and middle reaches (Xiao and Cheng, 2006). To resolve the conflict, the hydrological processes and water budget in the upper reaches of this river basin should be well elucidated (Cheng et al., 2006; Li et al., 2009). As aforementioned, vegetation plays an important role in soil water storage in forest watersheds. Hence, we focused on Picea crassifolia forest, Sabina przewalskii forest, and shrubs because they constitute the main forest types in the upper reaches of Heihe River Basin (Zhao et al., 2006; Xu et al., 2009).

This study aimed to determine the differences in soil properties and analyze the soil water retention and storage of different vegetations in the upper reaches of Heihe River Basin. A small catchment named Tianlaochi in the upper reaches of Heihe River Basin was selected to carry out the experiments. Tianlaochi was selected because it was slightly influenced by human activities. The catchment includes almost all the vegetation types in the upper reaches of Heihe River Basin.

\section{Study area and data analysis}

\subsection{Study area}

This study was conducted in the Tianlaochi catchment (covering $12.8 \mathrm{~km}^{2}$ ), which is located in the upper reaches of Heihe River in Northwest China (Fig. 1). The catchment has an altitude ranging from 2,700 to 4,446 $\mathrm{m}$ asl. It has a typical alpine climate with a mean annual precipitation of over $500 \mathrm{~mm}$, most of which occurs between June and September. The precipitation exhibits an increasing trend with the increase of elevation. The vegetation types in the study area include steppes composed of Carex tristachya, Polygonum viviparum L. and Plantago depressa, steppe-forests dominated by $P$. crassifolia and $S$. przewalskii, and sub-alpine shrubby meadows made up of Potentilla fruticosa L., Salix gilashanica C., Caragaha jubata and Spiraea alpina Pall, along with areas of alpine cold desert and permanent snow.

Three slope aspects, namely, south-facing slope (SS), north-facing slope (NS), and west-facing slope (WS) in the middle part of the catchment, were selected to carry out the experiments (Fig. 1). SS is a divergent-convex hill slope (Fig. 2a) with $S$. przewalskii forest (Fig. 2b). WS is a relatively planar 


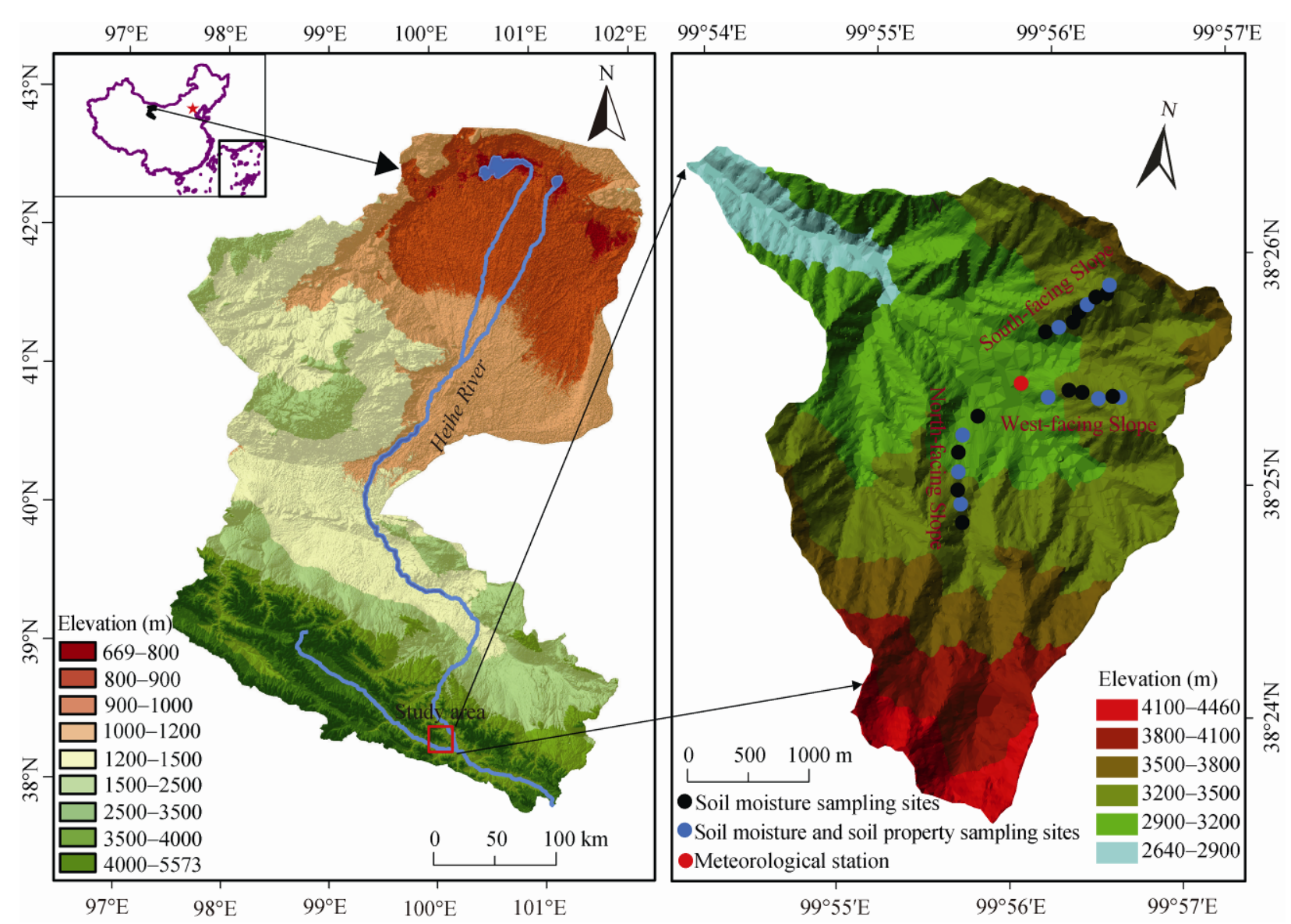

Fig. 1 The location of Tianlaochi catchment and the sampling sites in the catchment
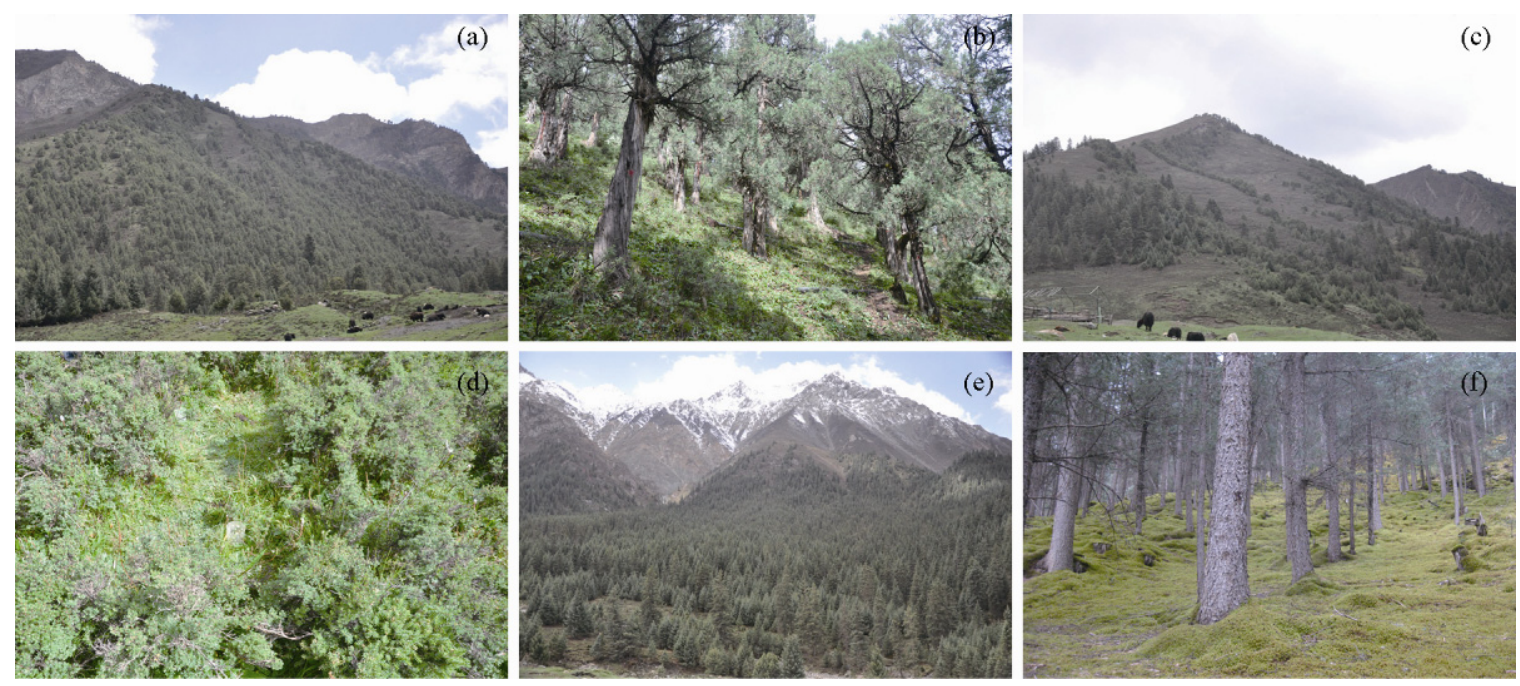

Fig. 2 Landscapes of the three study sites (a, south-facing slope; b, S. przewalskii forest; c, west-facing slope; d, shrubs; e, north-facing slope; $\mathrm{f}$, P. crassifolia forest)

hill slope (Fig. 2c) dominated by shrubs with $S$. przewalskii forest and P. crassifolia forest (Fig. 2d). NS is a convergent-concave hill slope (Fig. 2e) mainly covered by P. crassifolia forest (Fig. 2f). Table 1 showed the topographical characteristics and soil depths on the three slope aspects. 


\subsection{Sampling methods and data analysis}

During field investigation (from June to September 2011), 21 sampling sites were selected to measure soil moisture (Fig. 1). These sites are distributed along three profiles beginning from 3,100-m elevation with $50-\mathrm{m}$ intervals. The elevation ranges of the sampling sites in SS, WS, and NS were 3,100-3,430 m, $3,100-3,330 \mathrm{~m}$, and $3,100-3,400 \mathrm{~m}$, respectively. It was found that the spatial geometry has a significant impact on the average soil moisture over an area (Manfreda and Rodriguez-Iturbe, 2006). Furthermore, the composition of the vegetation should be taken into consideration when planning a spatial sampling of the soil moisture. In our study area, the land cover was clearly distinct on the three slope aspects. Specifically, $S$. przewalskii was distributed on the south-facing slope, shrubs on the west-facing slope, and P. crassifolia on the north-facing slope. More details of these three sites were showed in Table 1.

Soil samples at each site were collected from beneath the organic layer after litter removal. They were kept separately in aluminum boxes. At the same time, the undisturbed core samples were taken at different depths using standard core steel samplers (55-mm internal diameter and 45-mm height). Soil was sampled at a time interval of 10 days at five depths (0-10, 10-20, 20-30, 30-40, and 40-50 cm) from June to September 2011. Observation was subjoined after precipitation occurrence. Two duplicate samples were collected from each site. The soil moisture was measured by the conventional oven-dry method. Undisturbed core samples were dried with conventional oven method and weighted. Soil bulk dry density was calculated from oven-dried weight and the known volume of soil. The soil gravimetric water content was converted to soil volumetric water content by multiplying soil bulk density. Water content values at two duplicate points were averaged to one value per site.

\subsection{Sampling and measurement of soil physical properties}

Soil samples in three positions of each site (upslope, middle-slope, and downslope) at five depths were collected from beneath the organic layer after litter removal in 2011. They were kept separately in plastic bags. The soil samples were air dried at room temperature for one week and sieved through a 2-mm sieve to remove stones and roots and coarse debris. Soil passing the sieve was used to determine the soil organic matter content (SOM) and soil texture. Soil organic matter was measured using the dichromate oxidation method (Nelson and Sommers, 1982). Soil texture was measured using pipette method.

Soil textural fractions were obtained by weight according to the United States Department of Agriculture (USDA) method, which employs the following size standards: gravel $>2 \mathrm{~mm}, 2 \mathrm{~mm}<$ sand $<$ $0.05 \mathrm{~mm}, 0.05 \mathrm{~mm}<$ silt $<0.002 \mathrm{~mm}$, and clay $<$ $0.002 \mathrm{~mm}$ (Soil Survey Staff, 1999). In this paper, we only considered fractions of less than $2 \mathrm{~mm}$.

In order to understand the spatial variability of the soil properties in the study area, more sites of soil samples were selected and samples were collected at the depth of $0-10 \mathrm{~cm}$ (Fig. 3). The numbers of the sampling sites were 21 in $S$. przewalskii forest, 38 in shrubs, and 43 in $P$. crassifolia forest, respectively. Only soil bulk density and texture were measured for the 102 additional samples. After measurements, the Kolmogorov-Smirnov test (K-S test) was used to test the probability distribution of soil bulk density and texture in each vegetation cover and evaluate the differences of soil physical properties between $S$. przewalskii forest, shrubs and P. crassifolia forest. In general, the Kolmogorov-Smirnov test ( $\mathrm{K}-\mathrm{S}$ test) is a nonparametric test for the equality of continuous, one-dimensional probability distributions that can be used to compare a sample with a reference

Table 1 Topographic properties and soil depths of the three study sites

\begin{tabular}{cccc}
\hline & SS & WS & NS \\
\hline Elevation range $(\mathrm{m})$ & $3,100-3,429$ & $3,080-3,338$ & $3,084-3,419$ \\
Slope range $\left({ }^{\circ}\right)$ & $5.9-48.8$ & $1.6-34.5$ & $3.8-53.6$ \\
Soil depth $(\mathrm{cm})$ & $>100$ & $50-80$ & $30-50$ \\
\hline
\end{tabular}




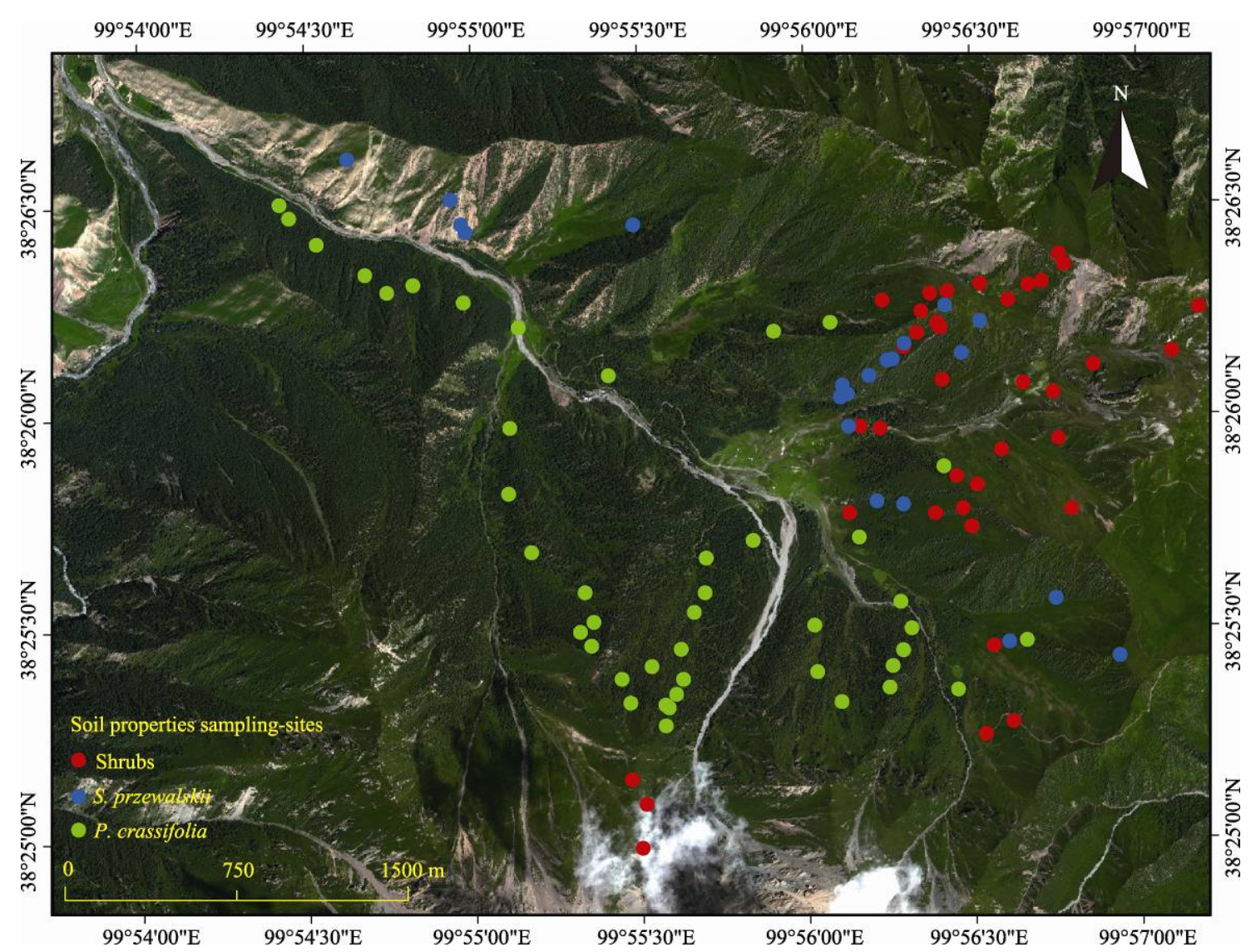

Fig. 3 The sampling sites for soil properties

probability distribution (one-sample $\mathrm{K}-\mathrm{S}$ test) or to compare two samples (two-sample K-S test).

The obtained soil texture and bulk density data were used as inputs for HYDRUS-1D model (Simunek et al., 2005) to estimate the soil water retention curves (SWRCs) for each sampling location. HYDRUS-1D implements the soil-hydraulic functions of van Genuchten (1980) who used the statistical pore-size distribution model of Mualem (1976) to obtain a predictive equation for the unsaturated hydraulic conductivity function in terms of soil water retention parameters. The expressions of van Genuchten (1980) are given by:

$$
\begin{gathered}
\theta(h)= \begin{cases}\theta_{r}+\frac{\theta_{s}-\theta_{r}}{\left[1+|\alpha h|^{n}\right]^{m}} & h<0 \\
\theta_{s} & h \geq 0\end{cases} \\
K(h)=K_{s} S_{e}^{l}\left[1-\left(1-S_{e}^{l / m}\right)^{m}\right]^{2}, m=1-1 / n, \quad n>1 .
\end{gathered}
$$

Where $\theta_{r}$ is the residual soil water content, $\theta_{s}$ is the saturated soil water content, $\alpha$ is the inverse of the air-entry value (or bubbling pressure), $n$ is a pore-size distribution index, $K(h)$ is the hydraulic conductivity, $S_{e}$ is the effective saturation, $K_{s}$ is the saturated hydraulic conductivity, and $l$ is the pore-connectivity parameter. The water retention parameters $\left(\theta_{r}, \theta_{s}, \alpha, n\right)$ and the saturated hydraulic conductivity $\left(K_{s}\right)$ were predicted by using soil textural class information, soil texture distribution and bulk density as inputs, followed by a hierarchical approach based on neural network analysis (Schaap et al., 1998). The pore-connectivity parameter $l$ in the hydraulic conductivity function was estimated (Mualem, 1976) to be approximately 0.5 as an average for many soils.

\section{Results}

\subsection{Soil properties and vegetation}

A total of 102 samples were collected to analyze the soil properties in different vegetation covers at the soil depth from 0 to $10 \mathrm{~cm}$. Table 2 a showed a summary of these soil properties. Table $2 \mathrm{~b}$ showed the probability 
distribution of these properties and significant differences among them under different vegetation types. From Table 2a, we found that the order of the mean soil bulk density in the three vegetation types is $P$. crassifolia $<$ shrubs $<S$. przewalskii, which may resulted from the accumulation of SOM. According to measurements of SOM, P. crassifolia forest has the largest SOM, while $S$. przewalskii forest has the lowest SOM (Table 3). The order of sand content is $P$. crassifolia $>$ shrubs $>S$. przewalskii. The relatively large value of coefficient variation $(\mathrm{CV})$ of sand content may be influenced by the variation of topography which could result in different soil transport and deposit dynamics. The change trend of soil bulk density and texture from different vegetation covers follows Gaussian distri- bution (one-sample $\mathrm{K}-\mathrm{S}$ test) (see Table 2b). According to the results of two-sample $\mathrm{K}-\mathrm{S}$ test, soil bulk density has significant differences, which might indicate that different vegetation covers could lead to different soil bulk densities. The differences of sand, silt and clay contents between S. przewalskii and $P$. crassifolia were not significant. But there was insignificant difference of soil texture between $S$. przewalskii and shrubs. There were also significant differences of silt and clay contents between $P$. crassifolia and shrubs.

The results of two-sample $\mathrm{K}-\mathrm{S}$ test (Table 3) showed significant differences in soil bulk density and texture among $P$. crassifolia forest, $S$. przewalskii forest, and shrubs $(\alpha=0.05)$. S. przewalskii forest and shrub soils were generally composed of finer grains

Table 2a Summary of soil properties in three vegetation covers

\begin{tabular}{|c|c|c|c|c|c|c|c|c|c|c|}
\hline Soil parameter $\left(\mathrm{g} / \mathrm{cm}^{3}\right)$ & Vegetation type & $\begin{array}{c}\text { Number of } \\
\text { sampling sites }\end{array}$ & Mean & Min. & Max. & $\mathrm{SD}$ & $\mathrm{CV}$ & Skewness & Kurtosis & Range \\
\hline \multirow{3}{*}{ Bulk density } & S. przewalskii & 21 & 0.90 & 0.48 & 1.56 & 0.30 & 0.33 & 0.46 & -0.57 & 1.08 \\
\hline & Shrubs & 38 & 0.74 & 0.43 & 1.18 & 0.19 & 0.26 & 0.61 & -0.46 & 0.75 \\
\hline & P. crassifolia & 43 & 0.49 & 0.17 & 1.00 & 0.18 & 0.37 & 0.59 & 0.19 & 0.83 \\
\hline \multirow{3}{*}{ Sand content } & S. przewalskii & 21 & 0.18 & 0.01 & 0.45 & 0.11 & 0.61 & 0.43 & 0.02 & 0.43 \\
\hline & Shrubs & 38 & 0.20 & 0.03 & 0.46 & 0.10 & 0.52 & 0.69 & 0.13 & 0.43 \\
\hline & P. crassifolia & 43 & 0.26 & 0.08 & 0.55 & 0.13 & 0.49 & 0.63 & -0.36 & 0.47 \\
\hline \multirow{3}{*}{ Silt content } & S. przewalskii & 21 & 0.50 & 0.13 & 0.68 & 0.16 & 0.33 & -1.12 & 0.55 & 0.54 \\
\hline & Shrubs & 38 & 0.53 & 0.09 & 0.72 & 0.16 & 0.31 & -1.16 & 0.68 & 0.63 \\
\hline & P. crassifolia & 43 & 0.48 & 0.14 & 0.71 & 0.12 & 0.26 & -0.36 & 0.32 & 0.57 \\
\hline \multirow{3}{*}{ Clay content } & S. przewalskii & 21 & 0.25 & 0.08 & 0.36 & 0.08 & 0.31 & -0.58 & -0.36 & 0.28 \\
\hline & Shrubs & 38 & 0.22 & 0.10 & 0.35 & 0.06 & 0.27 & 0.03 & -0.51 & 0.25 \\
\hline & P. crassifolia & 43 & 0.27 & 0.14 & 0.42 & 0.07 & 0.26 & 0.21 & -0.37 & 0.29 \\
\hline
\end{tabular}

Table $2 \mathbf{b} \quad \mathrm{K}-\mathrm{S}$ test results of soil properties from different vegetation types (including the level of significance, $\alpha=0.05$ )

\begin{tabular}{|c|c|c|c|c|}
\hline Item & Bulk density & Sand & Silt & Clay \\
\hline S. przewalskii forest (one-sample $\mathrm{K}-\mathrm{S}$ test) & $0.813^{* *}$ & $0.402^{* *}$ & $0.488^{* *}$ & $0.935^{* *}$ \\
\hline Shrubs (one-sample K-S test) & $0.596^{* *}$ & $0.967^{* *}$ & $0.297^{* *}$ & $0.913^{* *}$ \\
\hline P. crassifolia forest (one-sample $\mathrm{K}-\mathrm{S}$ test) & $0.327^{* *}$ & $0.522^{* *}$ & $0.880^{* *}$ & $0.990^{* *}$ \\
\hline S. przewalskii forest VS shrubs (two-sample K-S test) & $0.048^{++}$ & $0.883^{--}$ & $0.840^{--}$ & $0.184^{--}$ \\
\hline S. przewalskii forest VS P. crassifolia forest (two-sample K-S test) & $0.000^{++}$ & $0.319^{--}$ & $0.461^{--}$ & $0.854^{--}$ \\
\hline Shrubs VS P. crassifolia forest (two-sample K-S test) & $0.000^{++}$ & $0.095^{--}$ & $0.019^{++}$ & $0.044^{++}$ \\
\hline
\end{tabular}

Note: ${ }^{* *}$, the results accept the hypothesis that the test distribution is normal; ${ }^{--}$, the results accept the hypothesis that the two data samples come from the same distribution; ${ }^{++}$, the results reject the hypothesis that the two-data samples come from the same distribution. 
Table 3 Sampling sites and results of $\mathrm{K}-\mathrm{S}$ tests among $P$. crassifolia forest, S. przewalskii forest, and shrubs ( $\mathrm{Y}=$ significant difference, $\mathrm{N}=$ no significant difference)

\begin{tabular}{|c|c|c|c|c|c|c|c|c|c|c|}
\hline Site location & $\begin{array}{c}\text { Depth } \\
(\mathrm{cm})\end{array}$ & $\begin{array}{l}\text { Sand } \\
(\%)\end{array}$ & $\begin{array}{l}\text { Silt } \\
(\%) \\
\end{array}$ & $\begin{array}{l}\text { Clay } \\
(\%)\end{array}$ & $\begin{array}{c}\text { Organic carbon } \\
(\mathrm{g} / \mathrm{kg})\end{array}$ & $\begin{array}{c}\text { Bulk density } \\
\left(\mathrm{g} / \mathrm{cm}^{3}\right)\end{array}$ & Porosity & $\theta_{r}$ & $\theta_{s}$ & $\begin{array}{c}\mathrm{K}_{\mathrm{s}} \\
(\mathrm{L} / \mathrm{T}) \\
\end{array}$ \\
\hline \multicolumn{11}{|c|}{ South-facing slope (S. przewalskii forest) } \\
\hline \multirow{5}{*}{ Upslope } & $0-10$ & 22.53 & 56.90 & 20.57 & 84.93 & 0.99 & 0.63 & 0.08 & 0.52 & 121.84 \\
\hline & $10-20$ & 13.28 & 64.10 & 22.62 & 78.81 & 1.01 & 0.62 & 0.08 & 0.53 & 96.19 \\
\hline & $20-30$ & 7.97 & 69.43 & 22.60 & 60.81 & 1.06 & 0.60 & 0.09 & 0.53 & 67.90 \\
\hline & $30-40$ & 5.67 & 65.20 & 29.13 & 40.51 & 1.12 & 0.58 & 0.09 & 0.53 & 40.63 \\
\hline & $40-50$ & 6.35 & 60.49 & 33.16 & 29.63 & 1.28 & 0.52 & 0.09 & 0.49 & 17.08 \\
\hline \multirow{5}{*}{ Middle-slope } & $0-10$ & 26.60 & 55.90 & 17.50 & 65.56 & 1.05 & 0.61 & 0.07 & 0.48 & 101.68 \\
\hline & $10-20$ & 23.42 & 60.03 & 16.55 & 53.19 & 1.09 & 0.59 & 0.07 & 0.47 & 89.65 \\
\hline & $20-30$ & 20.08 & 60.43 & 19.48 & 46.34 & 1.11 & 0.58 & 0.07 & 0.48 & 71.93 \\
\hline & $30-40$ & 16.33 & 59.03 & 24.63 & 28.56 & 1.12 & 0.58 & 0.08 & 0.50 & 55.70 \\
\hline & $40-50$ & 14.82 & 58.43 & 26.75 & 22.51 & 1.22 & 0.54 & 0.08 & 0.49 & 32.42 \\
\hline \multirow{5}{*}{ Downslope } & $0-10$ & 18.40 & 59.73 & 21.87 & 68.65 & 1.16 & 0.57 & 0.08 & 0.48 & 50.71 \\
\hline & $10-20$ & 15.07 & 59.57 & 25.37 & 48.46 & 1.15 & 0.57 & 0.08 & 0.50 & 46.42 \\
\hline & $20-30$ & 11.28 & 61.90 & 26.82 & 50.53 & 1.13 & 0.58 & 0.09 & 0.51 & 47.12 \\
\hline & $30-40$ & 9.50 & 60.90 & 29.60 & 30.05 & 1.11 & 0.59 & 0.09 & 0.53 & 47.06 \\
\hline & $40-50$ & 10.00 & 60.70 & 29.30 & 22.58 & 1.17 & 0.56 & 0.09 & 0.51 & 35.41 \\
\hline \multicolumn{11}{|c|}{ West-facing slope (shrubs) } \\
\hline \multirow{6}{*}{ Upslope } & $0-10$ & 16.60 & 62.90 & 20.50 & 110.60 & 0.92 & 0.65 & 0.08 & 0.55 & 158.03 \\
\hline & $10-20$ & 8.68 & 69.10 & 22.22 & 99.50 & 1.02 & 0.62 & 0.09 & 0.54 & 83.09 \\
\hline & $20-30$ & 14.63 & 57.50 & 27.87 & 20.34 & 1.71 & 0.36 & 0.09 & 0.54 & 86.38 \\
\hline & $30-40$ & 12.07 & 67.07 & 20.87 & 80.26 & 1.09 & 0.59 & 0.08 & 0.51 & 70.23 \\
\hline & $40-50$ & 4.05 & 63.95 & 31.99 & 74.65 & 1.07 & 0.60 & 0.09 & 0.55 & 46.34 \\
\hline & $0-10$ & 19.07 & 64.10 & 16.83 & 115.08 & 0.88 & 0.67 & 0.08 & 0.55 & 212.88 \\
\hline \multirow{4}{*}{ Middle-slope } & $10-20$ & 14.68 & 69.97 & 15.35 & 89.32 & 0.91 & 0.66 & 0.08 & 0.55 & 184.86 \\
\hline & $20-30$ & 13.43 & 62.23 & 24.33 & 79.49 & 1.15 & 0.57 & 0.08 & 0.50 & 47.53 \\
\hline & $30-40$ & 19.60 & 54.80 & 25.60 & 45.66 & 1.41 & 0.47 & 0.08 & 0.42 & 11.20 \\
\hline & $40-50$ & 17.82 & 58.73 & 23.45 & 47.19 & 1.39 & 0.48 & 0.07 & 0.43 & 14.20 \\
\hline \multirow{5}{*}{ Downslope } & $0-10$ & 39.47 & 42.93 & 17.60 & 99.44 & 0.89 & 0.67 & 0.07 & 0.53 & 189.19 \\
\hline & $10-20$ & 26.15 & 52.57 & 21.28 & 65.82 & 1.11 & 0.58 & 0.07 & 0.50 & 63.91 \\
\hline & $20-30$ & 23.80 & 45.77 & 30.43 & 53.29 & 1.17 & 0.56 & 0.09 & 0.50 & 36.19 \\
\hline & $30-40$ & 24.40 & 52.60 & 23.00 & 65.87 & 1.24 & 0.53 & 0.07 & 0.45 & 29.86 \\
\hline & $40-50$ & 25.02 & 49.93 & 25.05 & 68.05 & 1.16 & 0.57 & 0.08 & 0.48 & 42.95 \\
\hline \multicolumn{11}{|c|}{ North-facing slope (P. crassifolia forest) } \\
\hline \multirow{5}{*}{ Upslope } & $0-10$ & 27.73 & 45.97 & 26.30 & 132.79 & 0.61 & 0.77 & 0.10 & 0.68 & 451.48 \\
\hline & $10-20$ & 31.13 & 46.80 & 22.07 & 143.04 & 0.55 & 0.79 & 0.10 & 0.69 & 555.93 \\
\hline & $20-30$ & 31.02 & 45.57 & 23.42 & 136.08 & 0.57 & 0.79 & 0.10 & 0.68 & 518.18 \\
\hline & $30-40$ & 29.43 & 48.83 & 21.73 & 126.57 & 0.65 & 0.76 & 0.09 & 0.65 & 440.66 \\
\hline & $0-10$ & 55.47 & 23.07 & 21.47 & 204.34 & 0.39 & 0.85 & 0.09 & 0.71 & 285.89 \\
\hline \multirow{3}{*}{ Middle-slope } & $10-20$ & 30.88 & 30.13 & 38.98 & 183.31 & 0.40 & 0.85 & 0.12 & 0.75 & 466.17 \\
\hline & $20-30$ & 39.47 & 37.77 & 22.77 & 154.11 & 0.58 & 0.78 & 0.10 & 0.68 & 449.31 \\
\hline & $30-40$ & 38.33 & 38.70 & 22.97 & 154.39 & 0.73 & 0.72 & 0.09 & 0.61 & 294.31 \\
\hline \multirow{5}{*}{ Downslope } & $0-10$ & 42.23 & 35.30 & 22.47 & 172.19 & 0.44 & 0.84 & 0.10 & 0.71 & 471.83 \\
\hline & $10-20$ & 40.47 & 35.77 & 23.77 & 166.62 & 0.56 & 0.79 & 0.10 & 0.69 & 436.64 \\
\hline & $20-30$ & 42.30 & 40.77 & 16.93 & 158.86 & 0.62 & 0.77 & 0.09 & 0.64 & 459.10 \\
\hline & $30-40$ & 31.17 & 35.43 & 33.40 & 122.79 & 0.58 & 0.78 & 0.11 & 0.71 & 448.19 \\
\hline & $40-50$ & 37.73 & 38.70 & 23.57 & 99.81 & 0.48 & 0.82 & 0.10 & 0.71 & 536.99 \\
\hline \multicolumn{2}{|c|}{ South-facing slope average } & 14.75 & 60.85 & 24.40 & 48.74 & 1.12 & 0.58 & 0.08 & 0.50 & 61.45 \\
\hline \multicolumn{2}{|c|}{ West-facing slope average } & 18.63 & 58.28 & 23.09 & 74.30 & 1.14 & 0.57 & 0.08 & 0.51 & 85.12 \\
\hline \multicolumn{2}{|c|}{ North-facing slope average } & 36.72 & 38.68 & 24.60 & 150.38 & 0.55 & 0.79 & 0.10 & 0.69 & 447.28 \\
\hline \multicolumn{2}{|c|}{ Total average } & 22.75 & 53.25 & 24.00 & 88.39 & 0.95 & 0.64 & 0.09 & 0.56 & 186.35 \\
\hline \multirow{3}{*}{$\mathrm{K}-\mathrm{S}$ Test } & SS VS WS & $\mathrm{N}$ & $\mathrm{N}$ & $\mathrm{N}$ & $\mathrm{Y}$ & $\mathrm{N}$ & $\mathrm{N}$ & $\mathrm{N}$ & $\mathrm{N}$ & $\mathrm{N}$ \\
\hline & SS VS NS & $\mathrm{Y}$ & $\mathrm{Y}$ & $\mathrm{N}$ & $\mathrm{Y}$ & $\mathrm{Y}$ & $\mathrm{Y}$ & $\mathrm{Y}$ & $\mathrm{Y}$ & Y \\
\hline & WS VS NS & $\mathrm{Y}$ & $\mathrm{Y}$ & $\mathrm{N}$ & $\mathrm{Y}$ & $\mathrm{Y}$ & $\mathrm{Y}$ & $\mathrm{Y}$ & $\mathrm{Y}$ & $\mathrm{Y}$ \\
\hline
\end{tabular}


compared with $P$. crassifolia forest soil (Table 3). The clay content (24.40\% for $S$. przewalskii forest, $23.09 \%$ for shrubs, and $24.60 \%$ for $P$. crassifolia forest) among the three vegetation types had no significant differences. However, the average organic carbon content (48.74 $\mathrm{g} / \mathrm{kg}$ for $S$. przewalskii forest, $74.30 \mathrm{~g} / \mathrm{kg}$ for shrubs, and $150.38 \mathrm{~g} / \mathrm{kg}$ for $P$. crassifolia forest) was significantly different. The average bulk density $\left(1.12 \mathrm{~g} / \mathrm{cm}^{3}\right.$ for $S$. przewalskii forest and $1.14 \mathrm{~g} / \mathrm{cm}^{3}$ for shrubs), porosity ( 0.58 for $S$. przewalskii forest and 0.57 for shrubs), $\theta_{r}$ (0.08 for $S$. przewalskii forest and 0.08 for shrubs), $\theta_{s}$ (0.50 for $S$. przewalskii forest and 0.51 for shrubs), and $K_{s}(61.45 \mathrm{~mm} / \mathrm{h}$ for $S$. przewalskii forest and $81.62 \mathrm{~mm} / \mathrm{h}$ for shrubs) displayed consistency. However, the average bulk density, porosity, $\theta_{r}, \theta_{s}$ and $K_{s}$ of both $S$. przewalskii forest and shrubs were significantly different from those of $P$. crassifolia forest $\left(0.55 \mathrm{~g} / \mathrm{cm}^{3}\right.$ for bulk density, 0.79 for porosity, 0.10 for $\theta_{r}, 0.69$ for $\theta_{s}$, and $447.28 \mathrm{~mm} / \mathrm{h}$ for $K_{s}$ ). Similarly, Geroy et al. (2011) reported significant differences in soil properties between the south-facing slope and the north-facing slope. In the present study, no significant relationship was found between clay content and slope aspect. But Famiglietti et al. (1998) reported that clay content is positively correlated with slope aspect. The value of $\theta_{s}$ is important to soil water retention (Geroy et al., 2011). In the present study, we found that the value

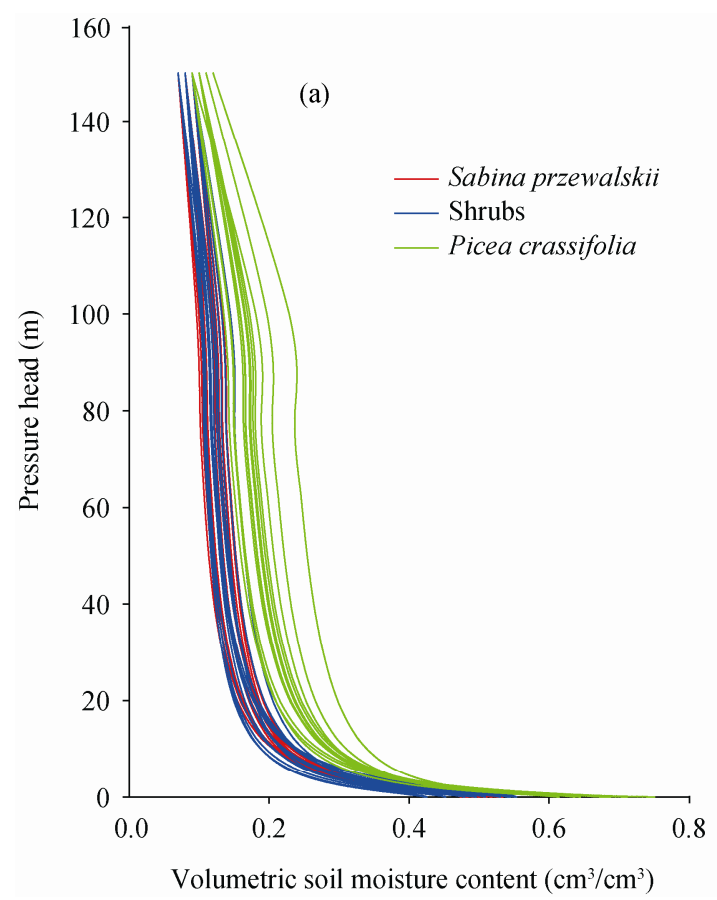

of $\theta_{s}$ is greater on the north-facing slope than on the south-facing slope. The result is consistent with the results of Leij et al. (2004), Herbst et al. (2006), and Geroy et al. (2011).

Based on the SWRCs obtained from the van Genuchten method using HYDRUS-1D model, we found that the soil retention water at $S$. przewalskii forest and shrubs showed no significant differences. The soil retention water at $S$. przewalskii forest and shrubs was less than at $P$. crassifolia forest (Fig. 4). At all pressure heads, the differences in moisture content between $S$. przewalskii forest and $P$. crassifolia forest were significant at the $95 \%$ confidence level.

\subsection{Soil moisture and vegetation}

The average soil moisture at the three vegetation types demonstrated similar temporal trends, although the vegetation types are different. Among the three slope aspects, $P$. crassifolia forest consistently had the highest averaged soil moisture, whereas $S$. przewalskii forest had the lowest (Fig. 5). The transect-average soil moisture was consistent with soil water retention at the three vegetation types. These data were consistent with the modeled differences in SWRCs. The averaged soil moisture in $S$. przewalskii forest was less than that in shrub species. The difference may be due to the higher solar radiation received, which caused

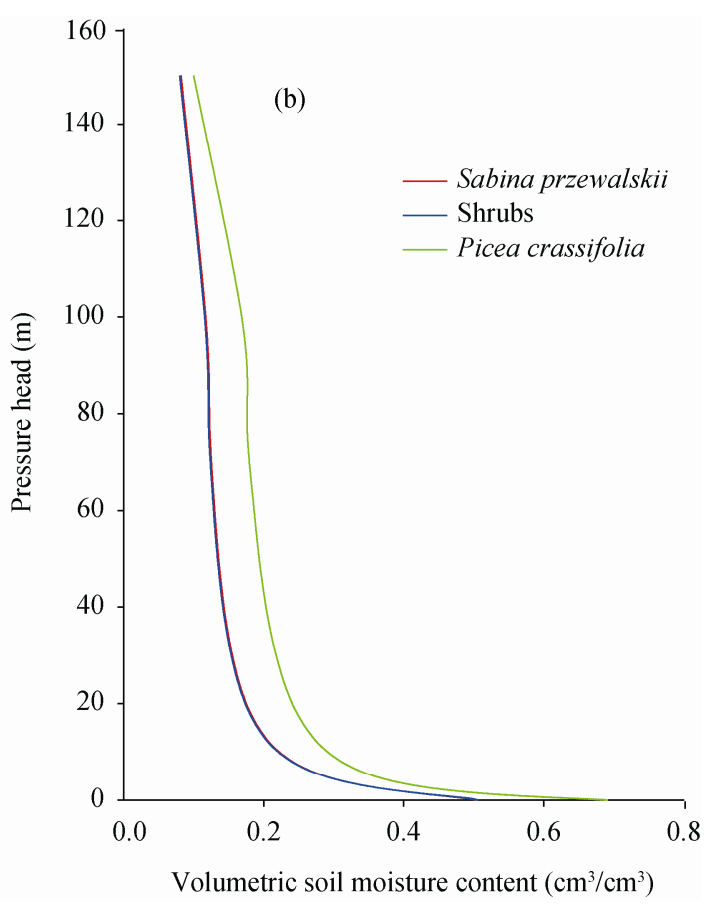

Fig. 4 Soil water retention curves (a, the SWRCs of sample locations; b, the averaged SWRCs in different vegetation types) 


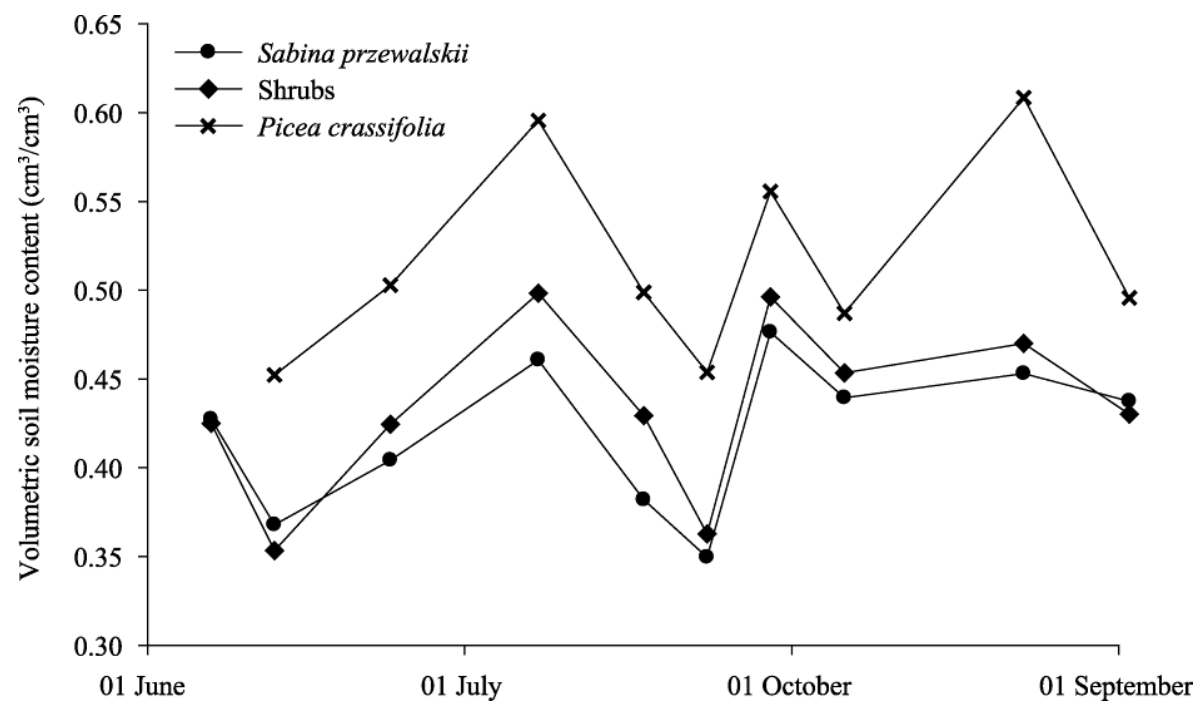

Fig. 5 The average soil moisture on the north-facing slope, west-facing slope and north-facing slope

higher evapotranspiration. However, the relative importance of soil hydraulic properties with respect to other driving factors including solar radiation, air temperature, and topography, is unknown.

\subsection{Soil water storage capacity and vegetation}

$\theta_{s}-\theta_{r}$ is the source of plant transpiration. Thus, higher soil water content may result in higher plant transpiration rate, in turn, leading to less recharge of water to rivers. The average value of $\theta_{s}-\theta_{r}$ at $P$. crassifolia forest $(58.62 \%)$ is larger than that at $S$. przewalskii forest $(42.13 \%)$ and shrub species (42.67\%). Therefore, the soil in P. crassifolia forest can store more water than that in S. przewalskii forest and shrubs at the similar depth. The soil in $P$. crassifolia forest could store $39.14 \%$ and $37.38 \%$ more water than $S$. przewalskii forest soil and shrub soil, respectively.

The saturated hydraulic conductivity $K_{s}$, which indicates soil infiltration and leakage, was 61.45, 85.12, and $447.28 \mathrm{~mm} / \mathrm{h}$ for $S$. przewalskii forest, shrubs, and P. crassifolia forest, respectively. Due to the relatively larger sand content and porosity, the $K_{s}$ in $P$. crassifolia forest is greatly larger than that in $S$. przewalskii forest and shrubs. Thus, during the same precipitation events, $P$. crassifolia forest can infiltrate more rainwater in soil. As a result, less surface flow and more subsurface flow will be generated as soil water content reaches saturation.

\subsection{Soil moisture and soil organic matter}

It is a fact that different vegetation covers result in different soil organic matter distribution, which is the main factor to influence the soil bulk density, soil water content and water retention. According to Fig. 6a (the black dotted line), there is a significant linear positive correlation between soil water content (SWC) and SOM at the level of $P<0.0001$. The correlation showed that SWC increases with the increase of SOM. However, different vegetation types have different trend lines. The low-value area in S. pzrewalskii forest indicated that this forest has low SWC and SOM. In contrary, the high-value area in $P$. crassifolia forest means that this forest has high SWC and SOM. The moderate-value area in shrubs is the overlapping regions of $S$. pzrewalskii forest and P. crassifolia forest. The results of significant tests showed that the linear positive correlation between SWC and SOM in $S$. pzrewalskii forest and shrubs are significant at the level of $P<0.0001$. However, there was no evident relationship between SWC and SOM in P. crassifolia forest. So it is necessary to conduct further investigation on the relationship between SWC and SOM in $P$. crassifolia forest.

Figure $6 \mathrm{~b}$ showed the relationship between SWC and SOM in different slope positions of $P$. crassifolia forest. The significance level of $P=0.05$ was performed because of the few sample number. In Fig. 6b, 

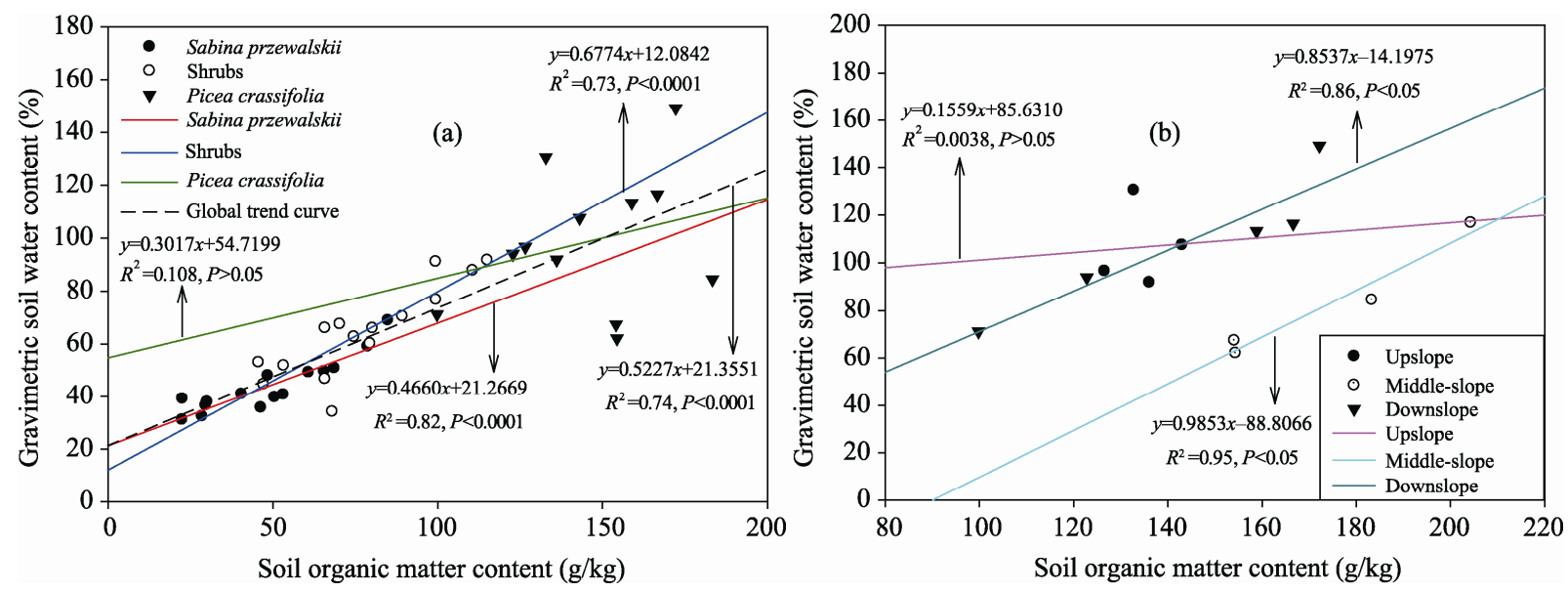

Fig. 6 The relationship between soil water content (SWC) and soil organic matter content (SOM) (a, the correlation between SWC and SOM in different vegetation types; $\mathrm{b}$, the correlation between SWC and SOM in different slope positions of $P$. crassifolia forest)

the significant tests of different slope positions showed that the linear positive correlation between SWC and SOM in downslope position and middle-slope position were significant at the level of $P<0.05$. The linear correlation between SWC and SOM in upslope position did not pass the significant test.

\section{Discussion and conclusions}

The greater silt fraction of the soil particles is inferred to be the dominant control on the increased soil water retention, especially in the dry end of the SWRC (Geroy et al., 2011). Soil organic matter, bulk density, and porosity affect soil water contents at or near saturation. In our study, although less silt and more sand fractions of the soil particles were found in P. crassifolia forest, more water was stored (Table 2; Figs. 4, 5). That may be attributed to the differences in soil organic matter content, porosity, and bulk density. Li et al. (2006) found that changes in soil properties are strongly related to vegetation pattern. Carey and Woo (2001) reported the organic layer thickness can reduce runoff and increase interflow. Meanwhile, Wang et al. (2010) collected soil samples from seven experimental sites in various climate zones ranging from humid temperate climate to temperate semi-arid climate and concluded that the quality of soil organic matter was more important than its quantity when determining soil wettability. This finding was supported by the research result in coniferous forestland. Yi et al. (2012) also reported that grassland degradation had effects on saturated soil water content due to variations in soil bulk density, which mainly affect soil capillary water-holding capacity. Wang et al. (2009) suggested that the variances of organic matter content in topsoil, fine-grained soil and surface litter layers caused differences in soil $K_{s}$ and water-holding capacity in the root layer under different vegetation covers. Zhang et al. (2011) studied the impact of vegetation and soil on runoff regulation in the headwater streams of the east Qinghai-Tibet Plateau, and found that forested ecosystems had greater water conservation capacities than shrub ecosystems did.

Field capacity $(\mathrm{h} \approx-340 \mathrm{~cm})$ (Dingman, 2002; Geroy et al., 2011) is used to define the available water capacity. Richards and Wadleigh (1952) defined available water capacity as the range of available water that can be stored in soil and for growing crops. As shown in Fig. 4, the pressure head corresponds to volumetric soil moisture contents of approximately $32.97 \%, 32.93 \%$, and $40.18 \%$ in S. przewalskii forest, shrubs, and $P$. crassifolia forest, respectively. The soil of $P$. crassifolia forest has approximately $21.87 \%$ and $22.02 \%$ more soil water content than the soil of $S$. przewalskii forest and shrubs, respectively. Hence, if the shrubs were displaced by $P$. crassifolia forest, it would store approximately $22.02 \%$ more soil water in the same soil depth. S. przewalskii forest would not transform into $P$. crassifolia forest because of its physiological characteristics, although it might be replaced by shrubs under degradation conditions. However, the differences in water retention were compli- 
cated by soil depths in different slopes. The soil depth ranges are $>100, \quad 50-80$, and $30-50 \mathrm{~cm}$ in $S$. przewalskii forest, shrubs, and $P$. crassifolia forest, respectively (Table 1). Thus, shrubs replaced by $P$. crassifolia forest could store more water in soils.

The soil layer with high organic matter content increased the water infiltration and water-holding capacity, which was reported in some researches (Wang et al., 2007, 2008, 2009). The same result was found in our study, as shown in Fig. 6. Therefore, the higher the soil organic matter content, the greater water storage capacity in the soil. However, there is a non-significant correlation between soil water content and soil organic matter content in $P$. crassifolia forest, which may result from sampling sites, vegetation cover, understory vegetation, soil properties, topography, and so on. Many studies have pointed out that it was difficult to identify the relative importance of vegetation cover, soil properties and topography for soil water content because of their mutual and multiple influences (Famiglietti et al., 1998; Western et al., 1999; Lin et al., 2006; Penna et al., 2009; Wang et al., 2012).

Nevertheless, the differences in soil properties resulted from the complex and durative interactions among climate, topography, biology, and soil parent materials over time. In this small watershed, although lithology is similar, the material sources, such as weathering and loess deposition, are enormously different. Furthermore, microclimate and topography also affect soil development. In general, the soils on the south-facing slope (S. przewalskii forest) receive more solar radiation than the soils on the west-facing slope (shrubs) and the north-facing slope (P. crassifolia forest). Even under similar precipitation rate and other environmental factors, more water could be lost on the north-facing slope. These factors lead to different vegetation types and densities, which influence soil density, soil organic carbon content, porosity, and texture. By linking litter production, quality and decomposition to vegetation succession, Zhang et al. (2012) found that the changes in vegetation type may have largely influenced carbon accumulation in the soil. This process could seriously influence soil organic matter content and soil bulk density. Once these properties are altered, soil hydraulic characteristics will change, leading to different soil water storage capacities and hydrological processes.
The present study focused on soil water storage capacity in a theoretical perspective. Understanding runoff generation and other processes is essential for better water management at the basin scale. Moreover, how other factors, such as evapotranspiration and soil depth, affect water retention in the catchment should also be elucidated. The effect of ecological restoration on the water resources in the inland basin is determined by establishing the impact of vegetation on water storage in a runoff-generating area. The high soil organic matter content and porosity in $P$. crassifolia forest allow it to store more water than $S$. przewalskii forest and shrubs (P. fruticosa L., Salix gilashanica C., C. juebata, and S. alpina Pall) at the same soil depth. As a result, these vegetation types produce different soil water retention capacities. These differences may be attributed to variations in vegetation heterogeneity due to the differences in solar radiation influenced by topography. The solar radiation on the south-facing slope increases water loss and alters the vegetation composition, which consequently influences soil properties. However, the impact of soil properties is complex. Therefore, future studies should integrate vegetation with topography, geology, and hydrology to gain a better understanding to soil water storage.

It should be noted that the current study only focused on the effect of vegetation on soil water retention and storage at the point scale rather than in the watershed scale. In fact, the analysis of the effect of vegetation on the mechanisms by which catchments retain water in soils may be conducted by field investigations on a real catchment or in a virtual laboratory. The later approach is usually implemented by using hydrological models which are able to reproduce all the processes that influence the water balance and runoff production in a watershed. Some published literatures (e.g. Bultot et al., 1990; Hundecha and Bardossy, 2004; Fiorentino et al., 2006) exploring the relationship between vegetation change and runoff at the watershed scale may provide good ideas to continue this research.

\section{Acknowledgements}

This study is sponsored by the National Natural Science Foundation of China (91025015). We are grateful to Zhang PENG, XiangLin ZHENG, YiYue LIU and Bei LIANG for their collaboration in field investigations and to Yao WANG and Yang ZHAO for their assistance in the soil survey. 


\section{References}

Bellot J, Escarre A. 1998. Stemflow and throughfall determination in a resprouted Mediterranean holm-oak forest. Annals of Forest Science, 55: 847-865.

Bultot F, Dupriez G L, Gellens D. 1990. Simulation of land use changes and impacts on the water balance-a case study for Belgium. Journal of Hydrology, 114: 327-348.

Carey S K, Woo M. 2001. Spatial variability of hillslope water balance, Wolf Creek basin, Subarctic Yukon. Hydrological Processes, 15: 3113-3132.

Castillo V M, Gómez-Plaza A, Martínez-Mena M. 2003. The role of antecedent soil water content in the runoff response of semiarid catchments: a simulation approach. Journal of Hydrology, 284: 114-130.

Cheng G D, Xiao H L, Xu Z M, et al. 2006. Water issue and its countermeasure in the inland river basins of northwest China: a case study in Heihe River Basin. Journal of Glaciology and Geocryology, 28(3): 406-413.

Dingman S L. 2002. Physical Hydrology ( $2^{\text {nd }}$ ed.). New Jersey: Prentice Hall, 646.

Eagleson P S. 2002. Ecohydrology: Darwinian Expression of Vegetation Form and Function. New York: Cambrige University Press.

Famiglietti J S, Rudicki J W, Rodell M. 1998. Variability in surface moisture content along a hillslope transect: Rattlesnake Hill, Texas. Journal of Hydrology, 210: 259-281.

Fiorentino M, Gioia A, Iacobellis V, et al. 2006. Analysis on flood generation processes by means of a continuous simulation model. Advances in Geosciences, 7: 231-236.

Gash J H C, Wright I R, Lloyd C R. 1980. Comparative estimates of interception loss from three coniferous forests in Great Britain. Journal of Hydrology, 48: 89-105.

Gash J H C, Lloyd C R, Lachaud G. 1995. Estimating sparse forest rainfall interception with an analytical model. Journal of Hydrology, 170: 79-86.

Geroy I J, Gribb M M, Marshall H P, et al. 2011. Aspect influences on soil water retention and storage. Hydrological Processes, 25: 3836-3842.

Herbst M, Diekkrüger B, Vereecken H. 2006. Geostatistical co-regionalization of soil hydraulic properties in a micro-scale catchment using terrain attributes. Geoderma, 132: 206-221.

Hundecha Y, Bárdossy A. 2004. Modeling of the effect of land use changes on the runoff generation of a river basin through parameter regionalization of a watershed model. Journal of Hydrology, 292: 281-295.

Leij F J, Romano N, Palladino M, et al. 2004. Topographical attributes to predict soil hydraulic properties along a hillslope transect. Water Resources Research, 40, W02407, doi: 10.1029/2002WR001641.

Li X, Li X W, Li Z Y, et al. 2009. Watershed allied telemetry experimental research. Journal of Geophysical Research, 114, D22103, doi: 10.1029/2008JD011590.

Li X R, Jia X H, Dong G R. 2006. Influence of desertification on vegetation pattern variations in the cold semi-arid grasslands of Qinghai-Tibet Plateau, North-west China. Journal of Arid Environments, 64: 505-522.

Lin H S, Kogelmann W, Walker C, et al. 2006. Soil moisture patterns in a forested catchment: a hydropedological perspective. Geoderma, 131: 345-368.

Liu S G. 1997. A new model for the prediction of rainfall interception in forest canopies. Ecological Modelling, 99: 151-159.

Lüscher P, Zürcher K. 2003. Flood Protection in Forests. Report of the Bavarian State Institute of Forestry, Report No. 40. Freising: Bavarian State Institute of Forestry.

Manfreda S, Rodrìguez-Iturbe I. 2006. On the spatial and temporal sampling of soil moisture fields. Water Resources Research, 42, W05409, doi: 10.1029/2005WR004548.

Miralles D G, Gash J H C, Holmes T R H, et al. 2010. Global canopy interception from satellite observations. Journal of Geophysical Research, 115, D16112, doi: 10.1029/2009JD013530.

Mualem Y. 1976. A new model for predicting the hydraulic conductivity of unsaturated porous media. Water Resources Research, 12: 513-522.

Murakami S. 2006. A proposal for a new forest canopy interception mechanism: Splash droplet evaporation. Journal of Hydrology, 319: $72-82$.

Nelson D W, Sommers L E. 1982. Total carbon, organic carbon, and organic matter. In: Page A L. Methods of Soil Analysis. Part 2: Chemical and Microbiological Properties. Madison: Soil Science Society of America, American Society of Agronomy.

Penna D, Borga M, Norbiato D, et al. 2009. Hillslope scale soil moisture variability in a steep alpine terrain. Journal of Hydrology, 364: 311-327.

Richards L A, Wadleigh C H. 1952. Soil water and plant growth. In: Shaw B T. Soil Physical Conditions and Plant Growth American Society of Agronomy Series Monographs, Volume II. New York: Academic Press, 74-251.

Sarah P. 2002. Spatial patterns of soil moisture as affected by shrubs, in different climatic conditions. Environmental Monitoring and Assessment, 73: 237-241.

Schaap M G, Leij F J, van Genuchten M T. 1998. Neural network analysis for hierarchical prediction of soil hydraulic properties. Soil Science Society of America Journal, 62: 847-855.

Seeger M, Errea M P, Beguería S, et al. 2004. Catchment soil moisture and rainfall characteristics as determinant factors for discharge/suspended sediment hysteretic loops in a small headwater catchment in the Spanish Pyrenees. Journal of Hydrology, 288: 299-311.

Simunek J, van Genuchten M T, Sejna M. 2005. The HYDRUS-1D Software Package for Simulating the One-Dimensional Movement of Water, Heat, and Multiple Solutes in Variably-Saturated Media. Riverside: University of California Riverside, 240. 
Soil Survey Staff. 1999. Soil Taxonomy, a Basic System of Soil Classification for Making and Interpreting Soil Surveys. $2^{\text {nd }}$ ed. Agriculture Handbook No. 436. Washington: USDA, Natural Resources Conservation Service, 869 .

Staelens J, de Schrijver A, Verheyen K, et al. 2008. Rainfall partitioning into throughfall, stemflow, and interception within a single beech (Fagus sylvatica L.) canopy: influence of foliation, rain event characteristics, and meteorology. Hydrological Processes, 22: 33-45.

Teske M E, Thistle H W. 2004. A library of forest canopy structure for use in interception modeling. Forest Ecology and Management, 198: 341-350.

van Genuchten M T. 1980. A closed-form equation for predicting the hydraulic conductivity of unsaturated soils. Soil Science Society of America Journal, 44: 892-898.

Wang G X, Li Y S, Wang Y B, et al. 2007. Impacts of alpine ecosystem and climatic changes on surface runoff in the source region of Yangtze River. Journal of Glaciology and Geocryology, 29(2): $159-168$.

Wang G X, Li Y S, Hu H C, et al. 2008. Synergistic effect of vegetation and air temperature changes on soil water content in alpine frost meadow soil in the permafrost region of Qinghai-Tibet. Hydrological Processes, 22: 3310-3320.

Wang G X, Li S N, Hu H C, et al. 2009. Water regime shifts in the active soil layer of the Qinghai-Tibet Plateau permafrost region, under different levels of vegetation. Geoderma, 149: 280-289.

Wang G X, Liu G S, Li C J. 2012. Effects of changes in alpine grassland vegetation cover on hillslope hydrological processes in a permafrost watershed. Journal of Hydrology, 444-445: 22-33.

Wang X Y, Zhao Y, Horn R. 2010. Soil wettability as affected by soil characteristics and land use. Pedosphere, 20: 43-54.

Western A W, Grayson R B, Bloschl G, et al. 1999. Observed spatial organization of soil moisture and its relation to terrain indices.
Water Resources Research, 35: 797-810.

Xiao H L, Cheng G D. 2006. Water issue and management at basin level in Heihe River, northwestern China. Journal of Desert Research, 26(1): 1-5.

Xiao Q F, McPherson E G, Simpson J R, et al. 1998. Rainfall interception by Sacramento's urban forest. Journal of Arboriculture 24: 235-244.

Xiao Q F, McPherson E G, Ustin S L, et al. 2000. Winter rainfall interception by two mature open-grown trees in Davis, California. Hydrological Processes, 14: 763-784.

Xu Z L, Zhao C Y, Feng Z D. 2009. A study of the impact of climate change on the potential distribution of Qinghai Spruce (Picea crassifolia) in Qilian Mountains. Acta Ecologia Sinica, 29: 278-285.

Yi X S, Li G S, Yin Y Y. 2012. The impacts of grassland vegetation degradation on soil hydrological and ecological effects in the source region of the Yellow River-a case study in Junmuchang region of Maqin country. Procedia Environmental Sciences, 13: 967-981.

Zhang K R, Cheng X L, Dang H, et al. 2012. Linking litter production, quality and decomposition to vegetation succession following agricultural abandonment. Soil Biology \& Biochemistry, doi: 10.1016/j.soilbio.2012.08.005.

Zhang W G, An S Q, Xu Z, et al. 2011. The impact of vegetation and soil on runoff regulation in headwater streams on the east Qinghai-Tibet Plateau, China. Catena, 87: 182-189.

Zhao C Y, Nan Z R, Cheng G D, et al. 2006. GIS-assisted modeling of the spatial distribution of Qinghai spruce (Picea crassifolia) in the Qilian Mountains, northwestern China based on biophysical parameters. Ecological Modeling, 191: 487-500.

Zheng H, Chen F L, Ouyang Z Y, et al. 2008. Impacts of reforestation approaches on runoff control in the hilly red soil region of southern China. Journal of Hydrology, 356: 174-184. 